\title{
Polymorphisms of the IL-18 promoter and bronchial asthma
}

\author{
SONG-QUAN WU ${ }^{1}$, WEI LIANG ${ }^{2}$, GUANG-LI WANG ${ }^{1}$, LING-YUN LI ${ }^{2}$, DAN-LI WANG ${ }^{1}$ and CONG CHEN ${ }^{1}$ \\ ${ }^{1}$ Medical Department of Lishui University; ${ }^{2}$ The People's Hospital of Lishui City, Lishui, Zhejiang 323000, P.R. China
}

Received May 22, 2012; Accepted September 18, 2012

DOI: $10.3892 / \mathrm{mmr} .2012 .1098$

\begin{abstract}
To study the association of polymorphisms of the IL-18 promoter (-607C/A and -137G/C) with bronchial asthma, 120 subjects with bronchial asthma were selected as the experimental group (49 cases with bronchial asthma and allergic rhinitis as experimental group 1 and 71 cases with bronchial asthma without allergic rhinitis as experimental group 2) and 120 healthy individuals were selected as the control group. A polymerase chain reaction sequence-specific primer (PCR$\mathrm{SSP}$ ) was used to identify the genotypic polymorphisms between the experimental and control groups. The results revealed that the frequencies of the $\mathrm{CC}, \mathrm{CA}$ and $\mathrm{AA}$ genotypes at $-607 \mathrm{C} / \mathrm{A}$ in experimental group 1 were $18.37,40.82$ and $40.82 \%$, respectively; these frequencies were $32.39,54.92$ and $12.68 \%$, respectively, in experimental group 2 . There was a statistically significant difference in the genotype distribution between experimental groups 1 and $2\left(\chi^{2}=12.81 ; \mathrm{P}<0.05\right)$. The allele frequencies of genotypes $\mathrm{C}$ and $\mathrm{A}$ were 38.78 and $61.22 \%$, respectively, in experimental group 1 and 59.86 and $40.14 \%$, respectively, in experimental group 2 . The allele frequencies at $-607 \mathrm{C} / \mathrm{A}$ were significantly different between experimental groups 1 and $2\left(\chi^{2}=10.32 ; \mathrm{P}<0.05\right)$. Frequencies of genotypes $\mathrm{GG}, \mathrm{GC}$ and $\mathrm{CC}$ at $-137 \mathrm{C} / \mathrm{A}$ in experimental group 1 were 48.98, 46.94 and 4.08\%, respectively, and 80.28, 14.08 and $4.08 \%$ in experimental group 2 with significant difference $\left(\chi^{2}=15.73, \mathrm{P}<0.05\right)$. Allele frequencies of $\mathrm{G}$ and $\mathrm{C}$ in experimental group 1 were 72.45 and $27.55 \%$, and 87.32 and $12.68 \%$ in experimental group 2 with statistically significant difference $\left(\chi^{2}=8.42, \mathrm{P}<0.05\right)$. In conclusion, polymorphisms of the IL-18 gene promoter at $-607 \mathrm{C} / \mathrm{A}$ and $-137 \mathrm{G} / \mathrm{C}$ were associated with allergic rhinitis in bronchial asthma, indicating that polymorphisms of the IL-18 gene promoter at $-607 \mathrm{C} / \mathrm{A}$ and $-137 \mathrm{G} / \mathrm{C}$ differentially affect the pathogenesis of asthma and allergic rhinitis.
\end{abstract}

Correspondence to: Professor Song-Quan Wu, Medical Department, Lishui University, Xueyuan Road, Lishui, Zhejiang 323000, P.R. China

E-mail: wusq20100429@126.com

Key words: bronchial asthma, allergic rhinitis, interleukin 18, polymorphism

\section{Introduction}

Bronchial asthma (referred to as asthma) is a common chronic inflammatory disease of the airways characterized by variable and recurring bronchospasm that causes periodic attacks of coughing, wheezing, shortness of breath and chest tightness (1). A small number of patients also present with chest pain as a main symptom. These symptoms may be initiated when patients are exposed to irritant gases or allergens and they are often exacerbated at night and/or in the morning (2). The principal pathological features of asthma include reversible bronchoconstriction, increased airway reactivity and increased inflammatory response (3). Studies have shown that the imbalance of different types of helper T cells (Th), particularly the imbalance of Th1/Th2 cells, may be the main cause of asthma. Specifically, increased numbers of Th2 cells and the secretion of inflammatory factors may be key factors in airway inflammation (4,5). Interleukin-18 (IL-18) regulates the immune response of Th1/Th2 cells, and polymorphisms of the IL-18 gene promoter are associated with diseases such as rheumatoid arthritis (6). This study investigated the association of asthma with polymorphisms of the IL-18 promoter at sites $-607 \mathrm{C} / \mathrm{A}$ and $-137 \mathrm{G} / \mathrm{C}$ by measuring these polymorphisms in asthma patients and in healthy individuals.

\section{Materials and methods}

Case records. The experimental group samples were collected from asthma patients $(n=120)$ diagnosed in The People's Hospital of Lishui (Zhejiang, China) from March 2007 to June 2011. The subjects comprised 59 men and 61 women and their median age was 25.58 years $( \pm 7.78$, range $15-37$ years). Among the asthma patients, 49 were cases of allergic rhinitis in asthma (experimental group 1) and 71 were without allergic rhinitis (experimental group 2). Healthy individuals $(n=120)$ who had received a health examination in the Physical Examination Center in the hospital were selected as a control group during the same time period. These individuals comprised 61 men and 59 women of median age, 36.89 years $( \pm 7.67$, range 15-37 years). No statistically significant differences in age or gender existed between the experimental and control groups. The Ethics Committee of Lishui University approved the study.

Genotype identification of IL-18 promoter at -607C/A and $-137 G / C$. A polymerase chain reaction sequence-specific primer (PCR-SSP) (7) was used to identify the genotypes of the IL-18 promoter at $-607 \mathrm{C} / \mathrm{A}$ and-137G/C. Primer 5 primer 


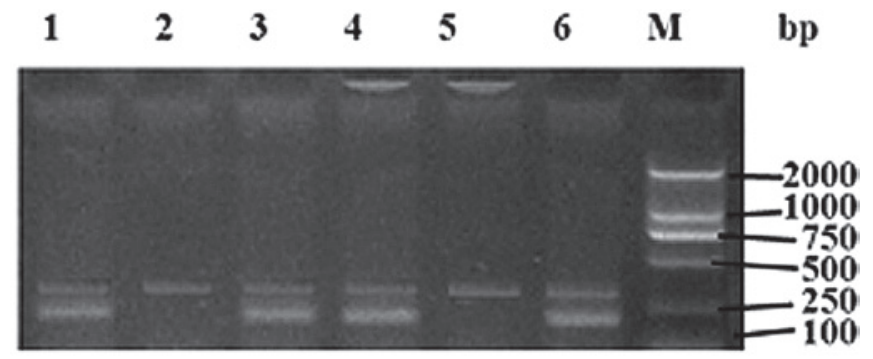

Figure 1. Electrophoresis of the IL-18 promoter region -607C/A site polymorphism. Lanes 1 and 2, CC genotype; lanes 3 and 4, CA genotype; lanes 5 and 6, AA genotype; M, DL2000 DNA marker.

design software was used to design specific F1, F2, common reverse and control forward primers of the promoter at $-607 \mathrm{C} / \mathrm{A}$ and-137G/C, respectively. Samples of venous blood $(5 \mathrm{ml})$ were obtained from all patients for extraction of genomic DNA by the phenolic-chloroform-isoamyl alcohol method (8). Polymerase chain reaction (PCR) was adapted to amplify the specific segment. The primer sequences for the promoter at the -607C/A site were: specific forward F1: 5'-GTTGCA GAAAGTGTAAAAATTATTAC-3'; specific forward F2: 5'-GTTGCAGAAAGTGTAAAAATTATTAA-3'; common reverse: 5'-CTTTGCTATCATTCCAGGAA-3'; and internal control forward: 5'-TAACCTCATTCAGGACTTCC-3'. The primer sequences for the promoter at the $-137 \mathrm{G} / \mathrm{C}$ site were: specific F1 forward: 5'-CCCCAACTTTTACGGAAG AAAAG-3'; specific F2 forward: 5'-CCCCAACTTTTACGG AAGAAAAC-3'; common reverse: 5'-CCAATAGGACTG ATTATTCCGCA-3'; and internal control forward: 5'-AGG AGGGCAAAATGCACTGG-3'. The primers were synthesized by Takara Biotech Co., Ltd. (Dalian, China). The specific forward primers F1 and F2 were used for all PCR reactions of each sample. The PCR reaction system included: $21 \mu 1$ genotype DNA; $2.5 \mu 1$ 10X PCR buffer (Promega Corp., Madison, WI, USA); $1.5 \mu \mathrm{ldNTP}$ (25 mmol/1, Promega Corp.); $0.25 \mu 1$ Taq DNA polymerase (2.5 U/ml, Promega Corp.); $1.5 \mu \mathrm{l} \mathrm{MgCl}_{2}$ (25 mmol/1, Promega Corp.); $0.5 \mu \mathrm{l}$ specific forward primer F1 or F2; $0.5 \mu 1$ common reverse primer; $0.5 \mu 1$ internal control forward primer; and water to a volume of $25 \mu \mathrm{l}$. PCR reaction conditions at $-607 \mathrm{C} / \mathrm{A}$ were as follows: 7 cycles of denaturation for $30 \mathrm{sec}$ at $94^{\circ} \mathrm{C}$; annealing for $40 \mathrm{sec}$ at $64^{\circ} \mathrm{C}$; extension for $45 \mathrm{sec}$ at $72^{\circ} \mathrm{C}$; then 30 cycles of denaturation for $60 \mathrm{sec}$ at $94^{\circ} \mathrm{C}$; annealing for $60 \mathrm{sec}$ at $57^{\circ} \mathrm{C}$; extension for $60 \mathrm{sec}$ at $72^{\circ} \mathrm{C}$; and a final extension for $5 \mathrm{~min}$ at $72^{\circ} \mathrm{C}$. PCR reaction conditions at $-137 \mathrm{G} / \mathrm{C}$ were as follows: 5 cycles of denaturation for $5 \mathrm{~min}$; denaturation for $30 \mathrm{sec}$ at $94^{\circ} \mathrm{C}$, annealing for $40 \mathrm{sec}$ at $68^{\circ} \mathrm{C}$; and extension for $60 \mathrm{sec}$ at $72^{\circ} \mathrm{C}$; then 30 cycles of denaturation for $60 \mathrm{sec}$ at $94^{\circ} \mathrm{C}$; annealing for $60 \mathrm{sec}$ at $62^{\circ} \mathrm{C}$; and extension for $60 \mathrm{sec}$ at $72^{\circ} \mathrm{C}$; and a final extension for $5 \mathrm{~min}$ at $72^{\circ} \mathrm{C}$.

Genotypes were determined from the bands obtained by agarose gel electrophoresis. The genotype CC at -607C/A gave a primer F1 product with two bands (301 and $196 \mathrm{bp}$ ) and a primer F2 product with one band (301 bp). The genotype CG yielded primer F1 and F2 products with two bands (301 and 196 bp). The genotype GG yielded a primer F1

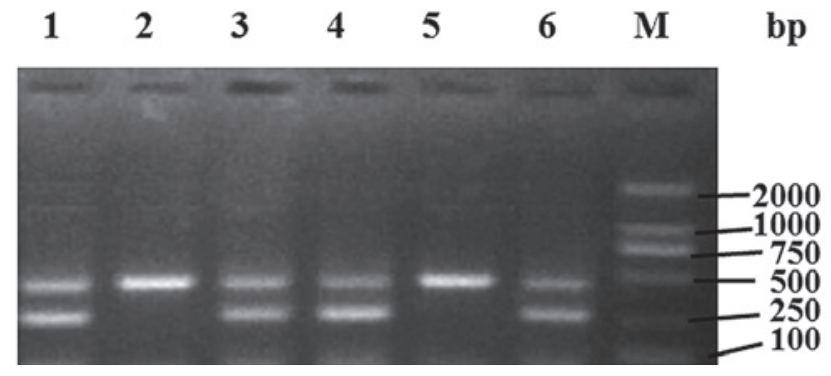

Figure 2. Electrophoresis of the IL-18 promoter region $-137 \mathrm{G} / \mathrm{C}$ site polymorphism. Lanes 1 and 2, GG genotype; lanes 3 and 4, GC genotype; lanes 5 and 6, CC genotype; M, DL2000 DNA marker.

product of one band (301 bp) and a primer F2 product of two bands (301 and 196 bp) (Fig. 1). For the genotype CC at $-137 \mathrm{G} / \mathrm{C}$, the primer $\mathrm{F} 1$ product produced two bands (261 and $446 \mathrm{bp}$ ) and the primer F2 product yielded one band (446 bp). For genotype GC, the products of primers F1 and F2 each produced two bands (261 and $446 \mathrm{bp}$ ). For genotype $\mathrm{CC}$, the primer F1 product produced one band (446 bp) and the primer F2 product yielded two bands (261 and 446 bp) (Fig. 2).

Statistical analysis. SPSS 13.0 for Windows (IBM, Armonk, NY, USA) statistical software was used for statistical analysis. The $\chi^{2}$ test was adopted to analyze the data and $\mathrm{P}<0.05$ was considered to indicate a statistically significant result.

\section{Results}

Polymorphism analysis of the IL-18 gene promoter at -607C/A. The genotype distributions and allele frequencies of the IL-18 gene promoter at $-607 \mathrm{C} / \mathrm{A}$ between the experimental and control groups conformed to the Hardy-Weinberg equilibrium. No statistically significant differences in the genotype distributions and allele frequencies between the experimental and control groups were identified $(\mathrm{P}>0.05)$. The frequencies of genotypes $\mathrm{CC}, \mathrm{CA}$ and $\mathrm{AA}$ in experimental group 1 were 18.37, 40.82 and $40.82 \%$, respectively, and in experimental group 2 were $32.39,54.92$ and $12.68 \%$, respectively. Therefore, there was a statistically significant difference in the genotype distribution at $-607 \mathrm{C} / \mathrm{A}$ between experimental groups 1 and 2 $\left(\chi^{2}=12.81 ; \mathrm{P}<0.05\right.$; Table I). The allele frequencies of $\mathrm{C}$ and $\mathrm{A}$ in experimental group 1 were 38.78 and $61.22 \%$, respectively, and in experimental group 2 were 59.86 and $40.14 \%$, respectively. There was a significant difference in the allele frequency at $-607 \mathrm{C} / \mathrm{A}$ between experimental groups 1 and $2\left(\chi^{2}=10.32\right.$; $\mathrm{P}<0.05)$.

Polymorphism analysis of the IL-18 gene promoter at $-137 G / C$. The genotype distributions and allele frequencies of the IL-18 gene promoter at $-137 \mathrm{G} / \mathrm{C}$ between the experimental and control groups conformed to the Hardy-Weinberg equilibrium. No statistically significant differences were identified in the genotype distributions and allele frequencies between the experimental and control groups $\left(\chi^{2}=15.73\right.$; $\mathrm{P}>0.05$; Table II). The frequencies of genotypes GG, GC and $\mathrm{CC}$ in experimental group 1 were $48.98,46.94$ and $4.08 \%$, 
Table I. Genotype and allele frequencies of IL-18 gene -607C/A site polymorphism.

\begin{tabular}{lccccccc}
\hline & & \multicolumn{3}{c}{ Genotype frequency } & & \multicolumn{2}{c}{ Allele frequency } \\
\cline { 3 - 5 } Groups & $\mathrm{n}$ & $\mathrm{CC}$ & $\mathrm{CA}$ & $\mathrm{AA}$ & $\mathrm{C}$ & $\mathrm{A}$ \\
\hline Control group & 120 & 30 & 49 & 41 & 109 & 131 \\
Experimental group & 120 & 32 & 59 & 29 & 123 & 117 \\
Experimental group 1 & 49 & 9 & 20 & 20 & 38 & 60 \\
Experimental group 2 & 71 & 23 & 39 & $9^{\mathrm{a}}$ & 85 & $57^{\mathrm{a}}$ \\
\hline
\end{tabular}

${ }^{\mathrm{a}} \mathrm{P}<0.05$ vs. experimental group 1.

Table II. Genotype and allele frequencies of IL-18 gene -137G/C site polymorphism.

\begin{tabular}{lccccccc}
\hline & & \multicolumn{3}{c}{ Genotype frequency } & & \multicolumn{2}{c}{ Allele frequency } \\
\cline { 3 - 5 } \cline { 5 - 7 } Groups & $\mathrm{n}$ & $\mathrm{GG}$ & $\mathrm{GC}$ & $\mathrm{CC}$ & $\mathrm{G}$ & $\mathrm{C}$ \\
\hline Control group & 120 & 83 & 32 & 5 & 198 & 42 \\
Experimental group & 120 & 81 & 33 & 6 & 195 & 45 \\
Experimental group 1 & 49 & 24 & 23 & 2 & 71 & 27 \\
Experimental group 2 & 71 & 57 & 10 & $4^{\mathrm{a}}$ & 124 & $18^{\mathrm{a}}$ \\
\hline
\end{tabular}

${ }^{\mathrm{a}} \mathrm{P}<0.05$ vs. experimental group 1.

respectively, and in experimental group 2 were $80.28,14.08$ and $4.08 \%$, respectively. Therefore, there was a significant difference in the genotype distribution at $-137 \mathrm{G} / \mathrm{C}$ between experimental groups 1 and $2\left(\chi^{2}=15.73 ; \mathrm{P}<0.05\right)$. The allele frequencies of $\mathrm{G}$ and $\mathrm{C}$ in experimental group 1 were 72.45 and $27.55 \%$, respectively, and in experimental group 2 were 87.32 and $12.68 \%$, respectively. Therefore, there was a statistically significant difference in the allele frequency at $-137 \mathrm{G} / \mathrm{C}$ between experimental groups 1 and $2\left(\chi^{2}=8.42\right.$; $\mathrm{P}<0.05)$.

\section{Discussion}

Studies have shown that an imbalance of Th1/Th2 cell function may cause asthma (9). Apter and Szefler (10) indicated that Th1 and Th2 cells had similar in vivo effects; for example, both were able to induce bronchial asthma, and cytokines from Th1 and Th 2 cells may cooperate to aggravate bronchial asthma symptoms. This contrasts with the earlier theory that Th1 and Th2 cytokines have contrasting effects on airway hyper- responsiveness (10). IL-18 is a member of the IL-1 family and is synthesized and secreted by a variety of immune effector cells. As a Th1-type cytokine, IL-18 is able to induce the occurrence of Th1-type cytokines, including IFN- $\gamma$ and TNF- $\alpha$, and contribute to the damage of tissues. However, IL-18 is also able to stimulate the expression of Th2 cytokines (11). IL-18 improves IgE and IgG1 expression in bronchioloalveolar eosinophils and increases cytokine release through the promotion of eosinophil activation. Therefore, IL-18 may trigger allergic inflammation by causing the accumulation of eosinophils and stimulating
IgE (12). The plasma IL-18 levels of children with asthma are significantly higher than those of healthy children $(13,14)$, thus IL-18 may be associated with the occurrence of bronchial asthma.

The current study analyzed the genotypes of the IL-18 gene promoter at $-607 \mathrm{C} / \mathrm{A}$ and $-137 \mathrm{G} / \mathrm{C}$ in patients with bronchial asthma and healthy individuals. The results indicated that there were no statistically significant differences in the genotype distributions and allele frequencies at $-607 \mathrm{C} / \mathrm{A}$ and $-137 \mathrm{G} / \mathrm{C}$ between subjects with bronchial asthma and healthy subjects. However, there were significance differences in genotype distributions and allele frequencies at $-607 \mathrm{C} / \mathrm{A}$ and $-137 \mathrm{G} / \mathrm{C}$ in patients with bronchial asthma and allergic rhinitis $(\mathrm{P}<0.05)$.

IL-18 is located at chromosome 11q22.2-22.3, which has two promoters upstream of exons 1 and 2 . The analysis of the IL-18 sequence revealed that the $-137 \mathrm{G} / \mathrm{C}$ site, located at the GATA3 binding site, is able to induce the expression of Th2 cytokines, while inactivation of GATA3 may reduce the airway inflammation in asthmatic mice. Furthermore, the presence of allele $\mathrm{G}$ is required for increased IL-18 expression following cell stimulation by PMA, but substitution with allele $\mathrm{C}$ attenuates this effect (15).

Pawlik et al (6) also found an association between polymorphisms of the IL-18 promoter at site $-607 \mathrm{C} / \mathrm{A}$ and severe bronchial asthma. The results of our study revealed that polymorphisms of the IL-18 gene promoter at $-137 \mathrm{G} / \mathrm{C}$ and $-607 \mathrm{C} / \mathrm{A}$ are not correlated with bronchial asthma without allergic rhinitis, but correlate with bronchial asthma with allergic rhinitis. As such, our results are not entirely consistent with the previous studies possibly to ethnic/geographic 
differences in the study populations. Further studies are required in diverse ethnic regions to elucidate the correlation of IL-18 promoter polymorphisms with asthma.

In brief, our results have shown that polymorphisms of the IL-18 gene promoter at $-137 \mathrm{G} / \mathrm{C}$ and $-607 \mathrm{C} / \mathrm{A}$ do not correlate with bronchial asthma, but correlate with allergic rhinitis in bronchial asthma. Polymorphisms of the IL-18 promoter at $-137 \mathrm{G} / \mathrm{C}$ and $-607 \mathrm{C} / \mathrm{A}$ may have unique effects on the pathogenesis of asthma and allergic rhinitis.

\section{References}

1. Krishnan JA, Lemanske RF Jr, Canino GJ, Elward KS, Kattan M, Matsui EC, et al: Asthma outcomes: symptoms. J Allergy Clin Immunol 129 (Suppl 3): S124-S135, 2012.

2. Wilson SR, Rand CS, Cabana MD, Foggs MB, Halterman JS, Olson L, et al: Asthma outcomes: quality of life. J Allergy Clin Immunol 129 (Suppl 3): S88-S123, 2012.

3. Mehring M, Gillissen A and Schneider A: Asthma - what is to do in general practice? MMW Fortschr Med 153: 47-51, 2011 (In German)

4. Tattersfield AE, Knox AJ, Britton JR and Hall IP: Asthma Lancet 360: 1313-1322, 2002.

5. Huang XZ,Zhuang JH, Ren YG,Zhou LJ and Zhou Q; Association of interleukin- 6 and interleukin-18 gene polymorphism with rheumatoid arthritis in Guangdong Han population. Nan Fang Yi Ke Da Xue Xue Bao 27: 1661-1664, 2007 (In Chinese).

6. Pawlik A, Kaminski M, Kuśnierczyk P, et al: Interleukin-18 promoter polymorphism in patients with atopic asthma. Tissue Antigens 70: 314-318, 2007.
7. Giedraitis V, He B, Huang WX and Hillert J: Cloning and mutation analysis of the human IL-18 promoter: a possible role of polymorphisms in expression regulation. J Neuroimmunol 112: 146-152, 2001

8. Panda DK, Miao D, Bolivar I, Li J, Huo R, Hendy GN and Goltzman D: Inactivation of the 25-hydroxyvitamin D 1alphahydroxylase and vitamin D receptor demonstrates independent and interdependent effects of calcium and vitamin D on skeletal and mineral homeostasis. J Biol Chem 279: 16754-16766, 2004.

9. Liu L, Jarjour NN, Busse WW and Kelly EA: Enhanced generation of helper $\mathrm{T}$ type 1 and 2 chemokines in allergen-induced asthma. Am J Respir Crit Care Med 169: 1118-1124, 2004.

10. Apter AJ and Szefler SJ: Advances in adult and pediatric asthma. J Allergy Clin Immunol 113: 407-414, 2004.

11. Volin MV and Koch AE: Interleukin-18: a mediator of inflammation and angiogenesis in rheumatoid arthritis. J Interferon Cytokine Res 31: 745-751, 2011.

12. Wild JS, Sigounas A, Sur N, et al: IFN-gamma-inducing factor (IL-18) increases allergic sensitization, serum IgE, Th2 cytokines, and airway eosinophilia in a mouse model of allergic asthma. J Immunol 164: 2701-2710, 2000.

13. Rachmiel M, Bloch O, Shaul AA, et al: Young patients with both type 1 diabetes mellitus and asthma have a unique IL-12 and IL-18 secretory pattern. Pediatr Diabetes 12: 596-603, 2011.

14. Melén E, Himes BE, Brehm JM, et al: Analyses of shared genetic factors between asthma and obesity in children. J Allergy Clin Immunol 126: 631-637.e1-8, 2010.

15. Imboden M, Nicod L, Nieters A, et al: The common G-allele of interleukin-18 single-nucleotide polymorphism is a genetic risk factor for atopic asthma. The SAPALDIA Cohort Study. Clin Exp Allergy 36: 211-218, 2006. 